\title{
Granulocyte colony-stimulating factor receptor signalling via Janus kinase 2/signal transducer and activator of transcription 3 in ovarian cancer
}

\author{
$J_{\text {Kumar }}^{1,2}$, F W Fraser ${ }^{1,2}$, C Riley ${ }^{3}$, N Ahmed ${ }^{3,4}$, D R McCulloch ${ }^{1,2}$ and A C Ward ${ }^{\star 1,2}$ \\ ${ }^{1}$ School of Medicine, Deakin University, Geelong, Victoria 3216, Australia; ${ }^{2}$ Strategic Research Centre in Molecular and Medical \\ Research, Deakin University, Geelong, Victoria 3216, Australia; ${ }^{3}$ Women's Cancer Research Centre, Royal Women's Hospital, \\ Parkville, Victoria 3052, Australia and 'Department of Obstetrics and Gynaecology, University of Melbourne, Parkville, \\ Victoria 3052, Australia
}

Background: Ovarian cancer remains a major cause of cancer mortality in women, with only limited understanding of disease aetiology at the molecular level. Granulocyte colony-stimulating factor (G-CSF) is a key regulator of both normal and emergency haematopoiesis, and is used clinically to aid haematopoietic recovery following ablative therapies for a variety of solid tumours including ovarian cancer.

Methods: The expression of G-CSF and its receptor, G-CSFR, was examined in primary ovarian cancer samples and a panel of ovarian cancer cell lines, and the effects of G-CSF treatment on proliferation, migration and survival were determined.

Results: G-CSFR was predominantly expressed in high-grade serous ovarian epithelial tumour samples and a subset of ovarian cancer cell lines. Stimulation of G-CSFR-expressing ovarian epithelial cancer cells with G-CSF led to increased migration and survival, including against chemotherapy-induced apoptosis. The effects of G-CSF were mediated by signalling via the downstream JAK2/STAT3 pathway.

Conclusion: This study suggests that G-CSF has the potential to impact on ovarian cancer pathogenesis, and that G-CSFR expression status should be considered in determining appropriate therapy.

Ovarian cancer is the most lethal gynaecological malignancy and the fourth leading cause of cancer mortality in women (GonzalezMartin et al, 2010). This is largely due to the asymptomatic nature of the disease, such that women with ovarian cancer typically present with advanced-stage disease, when the cancer has already spread throughout the peritoneum and, in some cases, to distant sites (Lengyel, 2010). With aggressive surgical manipulation and subsequent chemotherapy, most patients can return to a state of microscopic disease with minimal residual tumours. However, such remission is commonly short-lived, with $<40 \%$ survival at 5 years, due to recurrent disease (Gonzalez-Martin et al, 2010). In addition, much remains to be understood about the aetiology of ovarian cancer at the molecular level, which would form the basis of more effective therapeutic approaches.

The vast majority of ovarian cancers arise from malignant transformation of either the ovarian surface epithelium (OSE) (Hudson et al, 2008) or the secretory cells of Fallopian tube epithelium (FTE) (Colombo et al, 2010; Karst and Drapkin, 2010). The process by which it occurs remains poorly understood; however, it has been postulated that the repetitive inflammatory stress to OSE or FTE leads to the clonal expansion of OSE and/or FTE secretory cells forming a neoplastic precursor lesion, which 
ultimately gives rise to ovarian tumours (Colombo et al, 2010). One key event in the progression of the disease is the spread of tumour cells into the peritoneum where they survive as cellular aggregates or spheroids prior to attachment to a suitable secondary site for further growth, invasion and metastasis (Burleson et al, 2006; Shield et al, 2009). Tumour cells are known to secrete cytokines and growth factors (Punnonen et al, 1998; Zeimet et al, 1998; Zebrowski et al, 1999), resulting in autocrine and paracrine loops that are able to support the anchorage-independent growth of ovarian cellular aggregates and stimulate invasion (Ahmed et al, 2005; Shield et al, 2007). Indeed, stimulation of the epidermal growth factor receptor (EGFR) has already been strongly implicated in the progression of this disease (Colomiere et al, 2009; Xu et al, 2010; Zeineldin et al, 2010).

Cytokine receptors are divided into a number of groups based on structural characteristics, which often translate into functional similarities. This includes the so-called 'interleukin-6 receptor (IL-6R) family', which employ glycoprotein 130 (GP130) or related receptor chains for signal transduction via the Janus kinase/Signal transducer and activator of transcription (JAK2/STAT3) pathway. A number of studies have described roles for altered signalling from IL-6R family members as a contributing factor to a range of malignancies. For example, leukaemia inhibitor factor (LIF) has been shown to stimulate growth of pancreatic carcinomas (Kamohara et al, 2007); both IL-6 and oncostatin M (OSM) are able to stimulate proliferation of prostate cancer cells (Godoy-Tundidor et al, 2005), while granulocyte colony-stimulating factor (G-CSF) has similar roles in leukaemia (Katayama et al, 1998) and squamous cell carcinoma (Hirai et al, 2001). Autocrine activation appears to have a key role, as described for IL-6/IL-6R in a variety of tumours (Grivennikov and Karin, 2008) and G-CSF/GCSFR during malignant transformation in bladder cancer (Chakraborty et al, 2004). Meanwhile, activation of the downstream JAK2 and STAT3 has been shown to contribute to renal cell carcinoma (Wu et al, 2007), lung cancer (Gao et al, 2007) and breast cancer (Sansone et al, 2007), as well as ovarian cancer (Rose-John et al, 2007; Colomiere et al, 2009).

We and others have also demonstrated a role for aberrant IL-6/ IL-6R signalling in ovarian cancer (Wang et al, 2008; Colomiere et al, 2009). However, studies on the G-CSF/G-CSFR pathway have been more limited. This is significant because G-CSF has been employed to aid haematopoietic recovery following chemotherapy for a range of malignancies including ovarian cancer (Bohlius et al, 2003; Ray-Coquard et al, 2007). Therefore, the potential exists for deleterious effects from use of G-CSF as part of ovarian cancer therapy. This current study demonstrates that both G-CSF and G-CSFR are expressed on high-grade ovarian tumours and ovarian cancer cells, and that G-CSF/G-CSFR signalling via JAK2/STAT3 participates in ovarian cancer cell migration and resistance against apoptosis.

\section{MATERIALS AND METHODS}

Clinical samples. Ovarian epithelial tumours of different pathological grades were collected from patients diagnosed with highgrade ovarian carcinoma, after obtaining written informed consent under protocols approved by the Human Research and Ethics Committee (HREC \#09/09) of The Royal Women's Hospital, Melbourne, Australia, or via the Victorian Cancer Biobank and approved by the Deakin University Human Research Ethics Committee (DUHREC\#2010-104). The histopathological diagnosis and tumour grades were determined by staff pathologists as part of the clinical diagnosis. Normal ovaries needed for control comparisons were obtained from patients undergoing surgery as a result of suspicious ultrasound images or a family history of ovarian cancer. Specimens were snap-frozen under liquid nitrogen and subsequently stored at $-80{ }^{\circ} \mathrm{C}$ for expression analysis or preserved in Tissue-Tek (Torrance, CA, USA) embedding medium and frozen for immunohistochemical studies.

Cell lines. The human epithelial ovarian cancer lines TOV21G (Provencher et al, 2000), ES2, CAOV3, PA1 and SKOV3 (Fogh et al, 1977) were obtained from American Type Culture Collection, while OVCA433, OVCA429 and HEY (Ahmed et al, 2003) were obtained from Royal Women's Hospital Melbourne. Cell lines were grown as a monolayer in 25 or $75 \mathrm{~cm}^{2}$ flasks (BD Biosciences, Sydney, NSW, Australia) in a 1:1 mixture of medium 199 (Life Technologies, Melbourne, VIC, Australia) and MCDB105 (Sigma Aldrich, Sydney, NSW, Australia), supplemented with 10\% $(v / v)$ heat-inactivated fetal bovine serum and $2 \mathrm{~mm}$ glutamine (Life Technologies, Rockville, MD, USA) at $37^{\circ} \mathrm{C}$ with $5 \% \mathrm{CO}_{2}$. These cells were treated with recombinant human IL-6 $\left(10 \mathrm{ng} \mathrm{ml}^{-1}\right)$ or G-CSF $\left(10 \mathrm{ng} \mathrm{ml}^{-1}\right.$ ) (Cell Signaling, Beverly, MA, USA), cisplatin ( $5 \mu \mathrm{g} \mathrm{ml}^{-1}$, from saline solution) (Pfizer, Perth, WA, Australia) or paclitaxel $\left(1 \mu \mathrm{g} \mathrm{ml}^{-1}\right.$, from saline solution) (Hospira, Melbourne, VIC, Australia), with or without specific inhibitors for JAK2 (WP1066, $2.5 \mu \mathrm{M}$ ) and STAT3 (LLL12, $2.5 \mu \mathrm{M}$ ) (BioVision, Mountain View, CA, USA).

Immunohistochemistry. The expression of G-CSFR and relative activation status of STAT3 were assessed on paraffin-embedded primary tumour samples by immunohistochemistry as described previously (Colomiere et al, 2009). Briefly, tissue sections were blocked (1:50 human serum) and incubated with primary antibodies, washed and developed using appropriate secondary antibodies and the Peroxidase Universal Kit (Dako LSAB, Cambellfield, VIC, Australia) after elimination of non-specific peroxidase activity. Slides were counterstained with $1 \%(w / v)$ haematoxylin to highlight cell nuclei. Optical image capture and analysis was performed using AxioVision (Zeiss, North Ryde, NSW, Australia) and K5400 Zeiss software image analysis on a Zeiss Axioskop2 Microscope. Ten fields from each section were analysed in a 'blind' fashion and the percent tissue staining determined, which was scored as follows: $0(\leqslant 10 \%), 1(\geqslant 11-$ $25 \%), 2(\geqslant 26-50 \%), 3(\geqslant 51-75 \%), 4(\geqslant 76-90 \%)$ and $5(\geqslant 91-$ $100 \%)$. Control slides were processed in the absence of primary antibody, secondary antibody and chromogenic substrate, or with isotype control IgG to ensure specificity.

Flow cytometry. Cell lines were grown to confluence prior to harvest for fluorescence-activated cell sorter (FACS) analysis. Cell monolayers were washed twice with phosphate buffered saline (PBS), detached with $0.25 \%(w / v)$ trypsin-EDTA solution, collected by centrifugation and washed a further two times with PBS. Approximately $1 \times 10^{6}$ cells were fixed using $4 \%(w / v)$ paraformaldehyde (PFA) and subsequently blocked for $30 \mathrm{~min}$ in PBS containing $10 \%(v / v)$ goat serum. After incubation, the cells were washed twice with PBS, incubated with anti-G-CSFR-PE antibody (AbCam, Cambridge, MA, USA) at a concentration of $1 \mu \mathrm{g} \mu \mathrm{l}^{-1}$ for $30 \mathrm{~min}$, followed by three washes in PBS. Samples were analysed on FACS Canto (BD Bioscience) using FACS DIVA software, in comparison to appropriate controls.

Protein extraction and western blot analysis. Proteins were extracted using RIPA buffer containing complete protease inhibitors (Sigma Aldrich) according to the manufacturer's instructions. The concentration of the protein was estimated using a Pierce BCA Protein Determination Kit (Thermo Scientific, Asheville, NC, USA) following the manufacturer's instructions, with bovine serum albumin used as standards, and the absorbance at $562 \mathrm{~nm}$ determined using a Perkin Elmer VICTOR X Multilabel Plate Reader (Perkin Elmer, Glen Waverly, VIC, Australia). Western blot was performed as previously described (Gits et al, 2006), using the following monoclonal antibodies: anti- 
phospho-STAT3 (Tyr 705), anti-total-STAT3, anti-BCL2, antiphospho-ERK (Tyr 204), anti-total-ERK, anti-phosho-AKT (Ser 473), anti-total-AKT, anti-phospho-NF $\kappa$ B p65 (Ser 536), anti-total-NF $\kappa \mathrm{B}$ p65, and anti-ERCC1 (Cell Signaling), anti-glyceraldehyde 3-phosphate dehydrogenase (GAPDH) (Millipore Technologies, Sydney, NSW, Australia) and anti-CRP, anti-MDR1 and anti-GST-pi (AbCam). The secondary antibodies were anti-rabbit IRDye $680 \mathrm{CW}$ (red) and anti-mouse IRDye 800 CW (green) (LI-COR Biosciences, Lincoln, NE, USA).

EMSA. Nuclear extracts were prepared and analysed by electrophoretic mobility shift assay (EMSA) using the m67 high-affinity STAT-binding site probe, as described previously (Ward et al, 1999a).

ELISA. ELISA was performed using Human G-CSF Quantikine ELISA Kit (R\&D Systems, Minneapolis, MN, USA) as per the manufacturer's instructions.

Cell migration assay. The migratory potential of ovarian cancer cells was assessed as previously described (Lim et al, 2007). Briefly, cells were grown as a confluent monolayer in a six-well plate and then wounded using a sterile $200 \mu \mathrm{l}$ pipette tip. Three representative fields were marked and imaged immediately after wounding and $15 \mathrm{~h}$ later following incubation with cytokines and inhibitors as appropriate. Photos were taken using Olympus SC20 camera (Olympus, Tokyo, Japan) and the width of the scratches was measured at each time point and quantified using Cell Profilier (Lamprecht et al, 2007).

Growth assay. Cell growth rates in the presence and absence of cytokines were assessed as previously described (Ouellet et al, 2008). Briefly, $1 \times 10^{5}$ cells per well were seeded onto a six-well plate containing media with or without cytokines. Cells were trypsinised and resuspended in medium for counting using a hemocytometer daily over a 5-day period. Each experiment was performed in triplicate for each harvest and repeated twice.

Chemotaxis assay. Chemotaxis assays were performed using a two-chamber Transwell (Corning Inc, Tewksbury, MA, USA), as described previously (Zhao et al, 2011), using a polycarbonate filter with $3 \mu \mathrm{m}$ pores. Cells were trypsinised and suspended in medium containing $0.1 \%(v / v)$ FBS at a concentration of $1 \times 10^{5}$ cells per well. The cells were placed in the upper chamber and the medium containing $0.1 \%(v / v)$ was placed in the lower chamber. After $4 \mathrm{~h}$ at $37^{\circ} \mathrm{C}$, the cells in the upper chamber were wiped off with a cotton swab. The cells on the lower surface of the filter were fixed with $4 \%$ $(w / v)$ PFA for $1 \mathrm{~min}$ at room temperature, permeabilised with $100 \%(v / v)$ methanol, washed with PBS and stained with Giemsa solution (Sigma Aldrich). Migration was quantitated by selecting 10 different views and the number of migrated cells was calculated.

Apoptosis assay. Apoptosis assays were performed using flow cytometry analysis of cells doubly stained with anti-Annexin V-FITC and propidium iodide (PI) using an Apoptosis Detection Kit (BD Bioscience).

RNA extraction and semi-quantitative RT-PCR. Total RNA was extracted from cells using Trizol (Life Technologies) according to the manufacturer's instruction. The concentration and purity of RNA were determined using a Nanodrop ND-1000 spectrophotometer (Thermo Scientific). A $0.5 \mu \mathrm{g}$ per mg sample of RNA was used for cDNA synthesis using an iScript cDNA synthesis Kit (Bio-Rad, Gladesville, NSW, Australia) according to the manufacturer's instructions. PCR reactions were performed on a My-Cycler thermal cycler (Bio-Rad) using $25 \mu$ reaction volumes containing $500 \mathrm{ng}$ cDNA template, $5.5 \mu \mathrm{l}$ sterile nuclease-free water (Life Technologies), $12.5 \mu \mathrm{l} 2 \times$ GoTaq Green Master Mix containing TaqDNA polymerase, dNTPs, $\mathrm{MgCl}_{2}$ and reaction buffers at optimal concentrations (Promega, Alexandria, NSW, Australia) and $0.4 \mu \mathrm{M}$ of each gene-specific forward and reverse primers. The following primer pairs were used:

G-CSFR (CSF3R) 5' -CCTGGAGCTGAGAACTACCG-3'/5'-CT

TCTGAAGGCAGGTGGAG-3';

G-CSF (CSF3) 5'-CAGAGCTTCCTGGAGGTGTC-3'/5'-ATG

GGAGGACAGGAGCTTTT-3';

IL-6R $5^{\prime}$-CTCCTGCCAGTTAGCAGTCC-3 ${ }^{\prime} / 5^{\prime}$-TCTTGCCAG GTGACACTGAG- $3^{\prime}$;

IL-6 5'-TACCCCCAGGAGAAGATTCC-3 ${ }^{\prime} / 5^{\prime}$-TTTTCTGCCA GTGCCTCTTT-3';

BCL2 5 '-GGATGCCTTTGTGGAACTGT-3'/5'-AGCCTGCAG

CTTTGTTTCAT-3';

CRP $5^{\prime}$-ATACCCAGGCCACAAGAGTG-3' $/ 5^{\prime}$-ACGTCCTCTC AGCTTGGAAA-3';

$\beta$-ACTIN $5^{\prime}$-GGACTTCGAGCAAGAGATGG-3' ${ }^{\prime} / 5^{\prime}$-AGCACT GTGTTGGCGTACAG-3';

GAPDH (GAPD) 5' $5^{\prime}$ ATGTTCGTCATGGGTGTGAA-3'/5'-GT CTTCTGGGTGGCAGTGAT-3'.

Amplification conditions were typically $94{ }^{\circ} \mathrm{C}$ for $2 \mathrm{~min}$, followed by $94^{\circ} \mathrm{C}$ for $1 \mathrm{~min}, 58^{\circ} \mathrm{C}$ for $1.5 \mathrm{~min}$ and $72^{\circ} \mathrm{C}$ for $1 \mathrm{~min}$ for a total of 35 cycles, with a final condition of $72^{\circ} \mathrm{C}$ for $10 \mathrm{~min}$, unless otherwise specified. Control reactions were performed using no RT-control to confirm the absence of contaminating genomic DNA, and without cDNA template to ensure that amplicon products were not the result of contamination or primer-dimer effects on RT samples. PCR products were visualised on $1-3 \%(w / v)$ agarose gels containing SYBR Safe (Life Technologies) and imaged using a Chemidoc XRS Molecular Imager System (Bio-Rad).

Quantitative reverse transcriptase PCR (qRT-PCR). Gene expression was quantified by qRT-PCR on an Agilent Stratagene MX3000P. Reactions ( $25 \mu \mathrm{l}$ ) contained $3.125 \mu \mathrm{l}$ nuclease-free water, $3.125 \mu \mathrm{l}$ cDNA template (1:10 dilution), $12.5 \mu \mathrm{l}$ iQ $2 \mathrm{X}$ SYBR Green Supermix (Bio-Rad) and $3.125 \mu \mathrm{l}$ each of forward and reverse primer $(2.4 \mu \mathrm{M})$. Typical PCR conditions consisted of $95^{\circ} \mathrm{C}$ for $30 \mathrm{~s}$, followed by 45 cycles of $95^{\circ} \mathrm{C}$ for $10 \mathrm{~s}, 60^{\circ} \mathrm{C}$ for $30 \mathrm{~s}, 72^{\circ} \mathrm{C}$ for $20 \mathrm{~s}$, then $95^{\circ} \mathrm{C}$ for $1 \mathrm{~min}, 58^{\circ} \mathrm{C}$ for $1 \mathrm{~min}$, and finally incremental increases $\left(0.5^{\circ} \mathrm{C}\right)$ from $58^{\circ} \mathrm{C}$ to $95^{\circ} \mathrm{C}$ to establish the melting curve for each sample. Appropriate control reactions were performed to ensure products were not the result of DNA contamination or due to primer-dimer formation. Data retrieved from these assays were analysed using the Livak method (Livak and Schmittgen, 2001).

Statistical analysis. All statistical analyses were performed using GraphPad Prism 4 (GraphPad Software Ltd., La Jolla, CA, USA). Data were expressed as mean \pm s.e.m. The statistical correlation of data between groups was analysed by one-way analysis of variance (ANOVA) and a two-tailed Student's $t$-test, where $P<0.05$ was considered significant.

\section{RESULTS}

Expression of G-CSFR and its ligand in ovarian cancer. To investigate the role of G-CSFR in ovarian cancer, semi-quantitative RT-PCR was used to determine the expression of the genes encoding G-CSFR and its ligand G-CSF in a series of primary ovarian cancers of different grades in comparison to the genes encoding IL-6R and its ligand IL-6 (Figure 1A). This revealed strong G-CSFR expression in three out of four Grade 3 serous samples, with broad expression of G-CSF across all samples. IL-6R and IL-6 were expressed in a range of samples, irrespective of grade. The involvement of G-CSFR was further investigated on a panel of Grade 3 ovarian tumours by qRT-PCR (Figure 1B), which confirmed a majority of samples showed elevated levels of G-CSFR compared with normal controls. Immunohistochemistry 

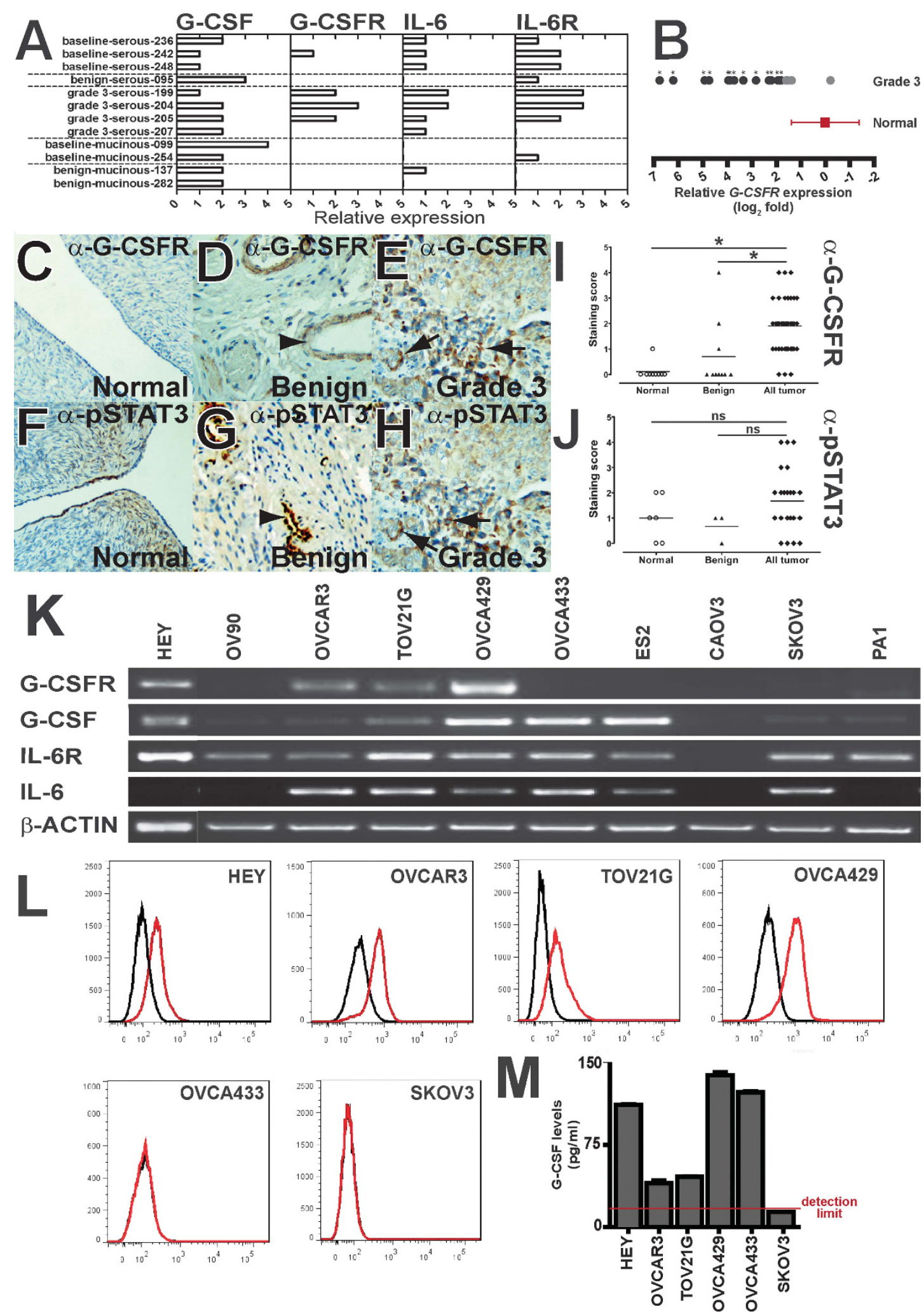

Figure 1. Expression of G-CSF/G-CSFR in ovarian cancer. (A-B) Expression of G-CSF/G-CSFR in primary ovarian cancers. RNA derived from the indicated patient samples were analysed with primers specific for G-CSF, G-CSFR, IL-6, IL-6R and $\beta$-ACTIN as a control. This analysis used either semiquantitative RT-PCR with expression of G-CSF, G-CSFR, IL-6 and IL-6R scored on a five-point scale on the indicated tumour samples (A), or by qRT-PCR for G-CSFR relative to $\beta$-ACTIN on Grades 3 tumour samples (B). (C-J) Detection of G-CSFR and phospho-STAT3 in ovarian cancer. Immunohistochemical staining of normal ovary $(\mathbf{C}, \mathbf{F})$, benign tumour $(\mathbf{D}, \mathbf{G})$ or Grade $3(\mathbf{E}, \mathbf{H})$ tumour samples with anti-G-CSFR (C-E) or anti-pSTAT3 $(\mathbf{F}-\mathrm{H})$, as indicated. Arrows indicate scattered epithelial staining with both antibodies in Grade 3 tumours, and arrowheads indicate vessel-associated staining. Immunohistochemical staining with anti-G-CSFR or anti-pSTAT3 was scored on a scale of 0-5, and represented as a scatter-plot for normal ovary, benign and pooled tumour groups, with the level of statistical significance indicated (I-J, ${ }^{*} P<0.05$, ns: not significant). (K-M) Expression of G-CSF/G-CSFR in a panel of ovarian cancer cell lines. Cells were analysed by RT-PCR for expression of the indicated genes (K), subjected to FACS analysis using anti-G-CSFR-PE (red line) or an isotype control (black line) (L), or conditioned media obtained and analysed for G-CSF by ELISA (M). 
on primary tissue sections confirmed an absence of G-CSFR expression on normal ovaries (Figure 1C), occasional weak staining on benign tumours (Figure 1D), but significant scattered epithelial staining within a cohort of tumours (Figure 1E), along with some vessel-associated staining. In total, $\sim 60 \%$ (22 out of 36 ) of tumour samples tested showed significant G-CSFR staining (score $\geqslant 2$ ), compared with $0 \%$ ( 0 out of 11$)$ in normal controls and $20 \%$ (2 out of 10) in benign tumours. Staining with anti-pSTAT3 revealed an overall low level epithelial staining on normal ovary and benign tumours (Figures $1 \mathrm{~F}$ and $\mathrm{G}$ ), but significant staining of vessels (Figure 1G). In contrast, a cohort of Grade 1-3 tumours again exhibited strong scattered pSTAT3 epithelial staining (Figure $1 \mathrm{H}$ ). Importantly, the majority of samples with a significant G-CSFR staining score were also positive for pSTAT3 staining (Figures 1I and J, and data not shown), consistent with active G-CSFR signalling.

The analysis of G-CSFR and its ligand was extended to a panel of ovarian cancer cell lines, with expression of $\beta$-ACTIN used as a control (Figure $1 \mathrm{~K}$ ). This revealed four cell lines (HEY, OVCAR3, TOV21G and OVCA429) that were positive for G-CSFR expression and all but two positive for G-CSF, confirming the two genes are not co-ordinately regulated. All cell lines except CAOV3 were positive for $I L-6 R$ and $I L-6$ was expressed in the majority, consistent with previous reports (Watson et al, 1990). FACS analysis was used to confirm cell-surface expression of G-CSFR (Figure 1L), with strong staining observed in the four cell lines that were positive for G-CSFR expression by RT-PCR, but not the two RT-PCR negative lines tested (OVCA433 and SKOV3). As it has been previously reported that stimulation with IL- 6 and EGF can affect the expression of IL-6 family cytokine receptors and their ligands (Colomiere et al, 2009), we also examined the relative expression of G-CSF/G-CSFR and IL-6/IL-6R following treatment with IL-6 and G-CSF. However, only modest changes were observed (Supplementary Figure 1). Finally, conditioned media were analysed using a G-CSF-specific ELISA, which confirmed robust production of G-CSF, particularly in HEY, OVCA429 and OVCA433 cells (Figure 1M), despite the latter not expressing G-CSFR.

G-CSF stimulates ovarian cancer cell migration. Having established the expression of G-CSFR in primary ovarian cancer samples and ovarian cancer cell lines, we sought to investigate the functional significance of this with regard to key cancer phenotypes. We first examined migration using a wound-healing assay (Jones et al, 2008), which was performed either without cytokines or in the presence of G-CSF or IL-6 (Figure 2A). Migration of cells after $15 \mathrm{~h}$ was found to be increased upon G-CSF stimulation in the G-CSFR-positive cell lines (OVCA429, HEY and TOV21G) but not in the G-CSFR-negative cell lines. In contrast, IL-6 enhanced migration in each of the cell lines tested, all of which were IL-6R-positive.

We next explored whether the migration observed was part of a chemotactic response using a Transwell assay to measure directional cell migration. Addition of G-CSF again increased migration in all G-CSFR-positive cell lines (Figure 2B). However, no significant difference in migration was observed whether the G-CSF was placed in the upper or lower chamber (data not shown), suggesting G-CSF-stimulated increased cell migration was not chemotactic in nature.

G-CSF does not affect proliferation but protects against apoptosis. Cytokines are known to stimulate proliferation and survival in responsive cells. Therefore, we examined those parameters in ovarian cancer cell lines in the presence or absence of cytokines. IL-6 elicited a significant increase in proliferation in all cell lines, but no enhancement in proliferation was observed with G-CSF (Figure 2C). We next sought to investigate the possible effects of G-CSF on survival. However, the cell lines tested showed very low levels of apoptosis, even in low serum, and so apoptosis was induced by the addition of sodium azide $(0.5 \%)$ in order to evaluate anti-apoptotic responses. G-CSF was able to provide variable but statistically significant protection against apoptosis in all G-CSFR-positive cell lines (Figure 2D). IL-6 also generally enhanced survival in this setting.

Effects of G-CSF are mediated by the JAK2/STAT3 pathway. Granulocyte colony-stimulating factor is known to activate many different signalling pathways, but principal among these is the JAK2/STAT3 pathway (Ward, 2007). To investigate whether this was functionally important in ovarian cancer cells, lysates were prepared from cell lines stimulated with G-CSF or IL-6 as a control, and analysed for STAT3 activation using phosphoSTAT3-specific antibodies (Figure 3A). Stimulation of the G-CSFR-positive cells OVCA429, HEY and TOV21G with G-CSF led to robust phosphorylation of STAT3, whereas the G-CSFR-negative OVCA433 and SKOV3 did not show STAT3 phosphorylation upon G-CSF stimulation. In contrast, all cell lines showed IL-6-induced STAT3 phosphorylation. Antibodies to detect total levels of STAT3 and GAPDH confirmed equivalent loading in each case. To verify the integrity of the JAK2/STAT3 pathway in these cells, specific inhibitors for JAK2 and STAT3 were used in combination with cytokine stimulation. Both inhibitors effectively blocked STAT3 phosphorylation by both cytokines (Figure $3 \mathrm{~B}$ ). The potential activation of ERK and AKT was also examined using phospho-specific antibodies (Figure $3 \mathrm{C}$ ). G-CSF induced strong activation of ERK, but not AKT, in these cells, despite robust activation of AKT by IL-6. The addition of a JAK2 inhibitor was able to block the G-CSF-mediated ERK activation (Figure 3D), indicating it lay downstream of JAK2. To confirm that signalling via the JAK2-STAT3 pathway also contributed to the G-CSF-induced phenotypes, responsive cell lines were re-analysed in combination with the specific inhibitors. Both inhibitors were able to suppress G-CSF-mediated migration (Figure $3 \mathrm{E}$ and Supplementary Figure 2) and survival responses (data not shown).

We next examined whether the effects of G-CSF on STAT3 phosphorylation translated into active STAT3-mediated transcription. Nuclear extracts were analysed by EMSA using a STAT3binding site. G-CSF induced strong binding to this probe, which was also blocked by both JAK2 and STAT3 inhibitors (Figure 4A). The expression of two STAT3-responsive genes, CRP and BCL2, was then examined by RT-PCR. This revealed strong induction of both genes by G-CSF in the G-CSFR-positive cell lines, OVCA429, HEY and TOV21G, but not in the G-CSFR-negative cell lines OVCA433 and SKOV3 (Figure 4B). This was confirmed by both qRT-PCR (Figure 4C) and western blot analysis (Figure 4D). The addition of JAK2 or STAT3 inhibitors effectively blocked the induction of BCL2 (Figure 4E), confirming it as a STAT3 target.

Interaction between chemotherapy agents and the G-CSF/ G-CSFR pathway. Both cisplatin and paclitaxel are common and effective chemotherapy treatments for ovarian cancer patients (Neijt et al, 2000; Bookman, 2012). Hence, it was relevant to investigate the status of G-CSF and G-CSFR expression in response to these chemotherapeutic agents in ovarian cancer cells. Addition of cisplatin resulted in increased expression of G-CSFR (nearly two- to fourfold) in the four cell lines tested and of G-CSF (nearly two- to fivefold) in three of these lines, as determined by real-time PCR (Figure 5A). This was further confirmed by ELISA on cell supernatants, which identified increased levels of secreted G-CSF in two of the cell lines, albeit to a modest extent (Figure 5B), and by FACS analysis, which showed increased levels of cell-surface G-CSFR on the four cell lines identified by qRT-PCR, but not SKOV, CAOV3, ES2 or PA1 (Figure 5C, and data not shown). Addition of paclitaxel led to a similar induction of G-CSF and G-CSFR (Figures 5D and E). The transcription factor $\mathrm{NF} \kappa \mathrm{B}$ is 
A
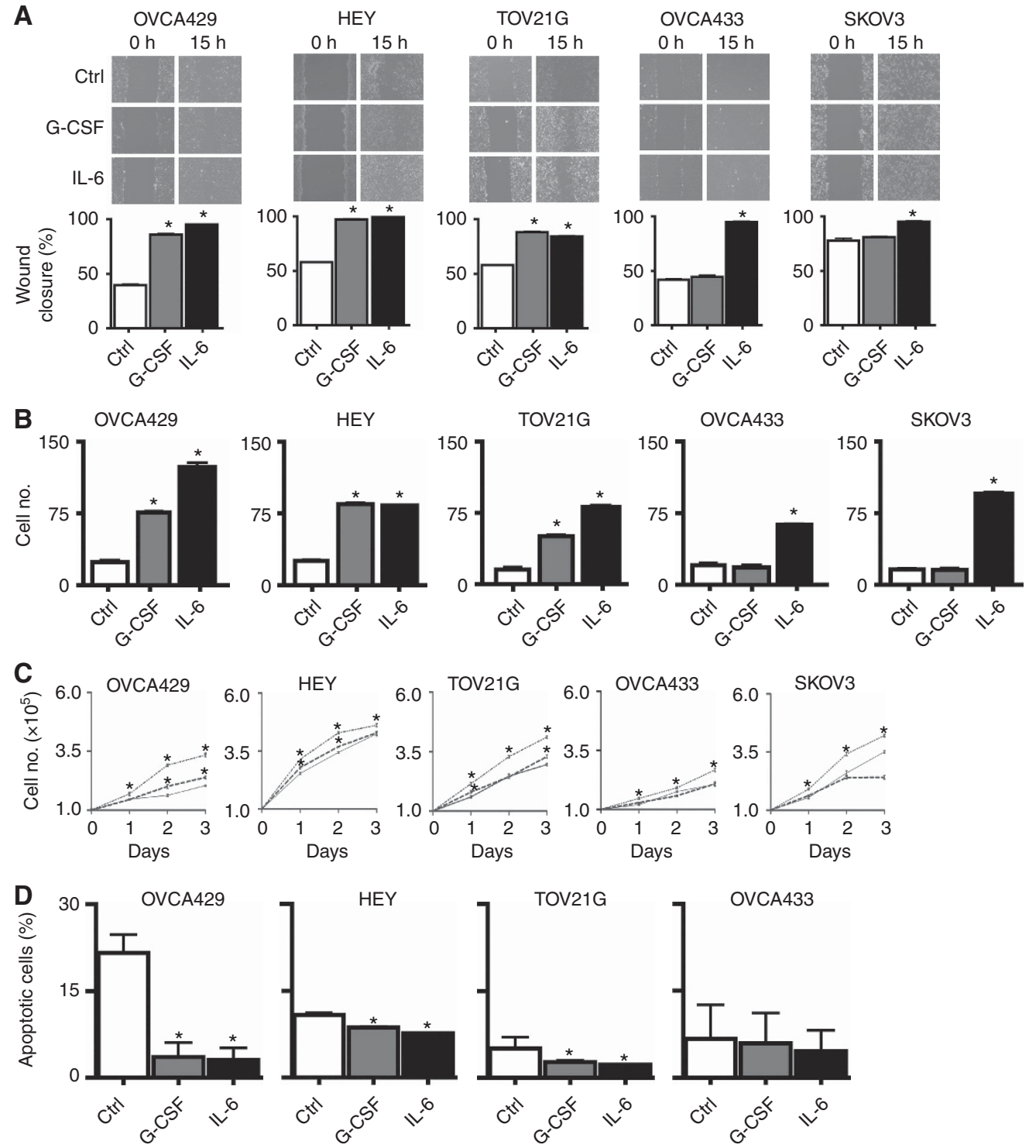

OVCA433

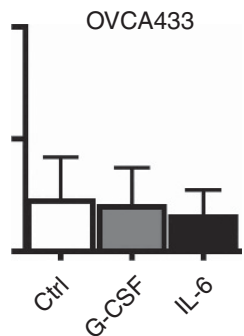

Figure 2. Phenotypic effects of G-CSF on G-CSFR-positive ovarian cancer cells. (A) Wound-healing assay. Indicated cells were incubated in a medium lacking cytokines (Ctrl) or containing G-CSF $\left(10 \mathrm{ng} \mathrm{ml}^{-1}\right)$ or IL-6 $\left(10 \mathrm{ng} \mathrm{ml}^{-1}\right)$. Images are representative of single independent experiments performed in triplicate. Graphs represent the mean percentage area of wound closure from three independent experiments $\left({ }^{\star} P<0.05\right)$. (B) Transwell migration assay. Indicated cells were analysed for migration in a transwell chamber in the presence and absence of G-CSF and IL-6. Mean number of cells migrated through the chamber was counted from five different areas from three independent experiments $\left({ }^{\star} P<0.05\right)$. (C) Proliferation assay. Indicated cells were incubated over a period of 5 days in the presence and absence of G-CSF and IL-6. The graph represents the mean cell count of three independent experiments ( $\left.{ }^{\star} P<0.05\right)$. (D) Apoptosis assay. Indicated cells were treated with sodium azide alone (Ctrl) or in the presence of G-CSF and IL-6. Graph shows the mean percentage of apoptotic cells $\left({ }^{\star} P<0.05\right)$.

known to be activated by chemotherapeutic agents (Lagunas and Melendez-Zajgla, 2008) and to regulate genes encoding cytokines (Lawrence, 2009), including G-CSF (Dunn et al, 1994). Treatment with either cisplatin or paclitaxel induced $\mathrm{NF} \kappa \mathrm{B}$ activation (Figure 5F), suggesting that it may be involved in the induction of G-CSF and potentially G-CSFR.

Cisplatin was found to enhance wound closure to a similar extent of that induced by G-CSF (Figure 6A), which was blocked by inhibitors of the JAK2/STAT3 pathway (Figure 6A and Supplementary Figure 3), shown to be effective in this setting (Figure 6B). Both cisplatin and paclitaxel were also able to induce significant apoptosis in these cell lines (Figures 6C and D, respectively). This could be ameliorated by treatment with G-CSF (or IL-6), but not in the presence of STAT3 or JAK2 inhibitors, consistent with robust activation of STAT3 by G-CSF in combination with either agent (Figure 7A). In this context, ERK was also activated by G-CSF, but not AKT (Figure 7B). Finally, G-CSF was able to induce MDR1, GST-pi and ERCC1 to various extents in all three cell lines tested, including in the presence of cisplatin or paclitaxel (Figure 7C), suggesting these proteins likely contribute to the G-CSF-induced chemoresistance phenotype.

\section{DISCUSSION}

The G-CSFR is expressed on a range of haematopoietic cells including haematopoietic stem cells, myeloid progenitors, mature neutrophilic granulocytes, monocytes and lymphocytes, as well non-haematopoietic tissues including cardiomyocytes, neuronal 


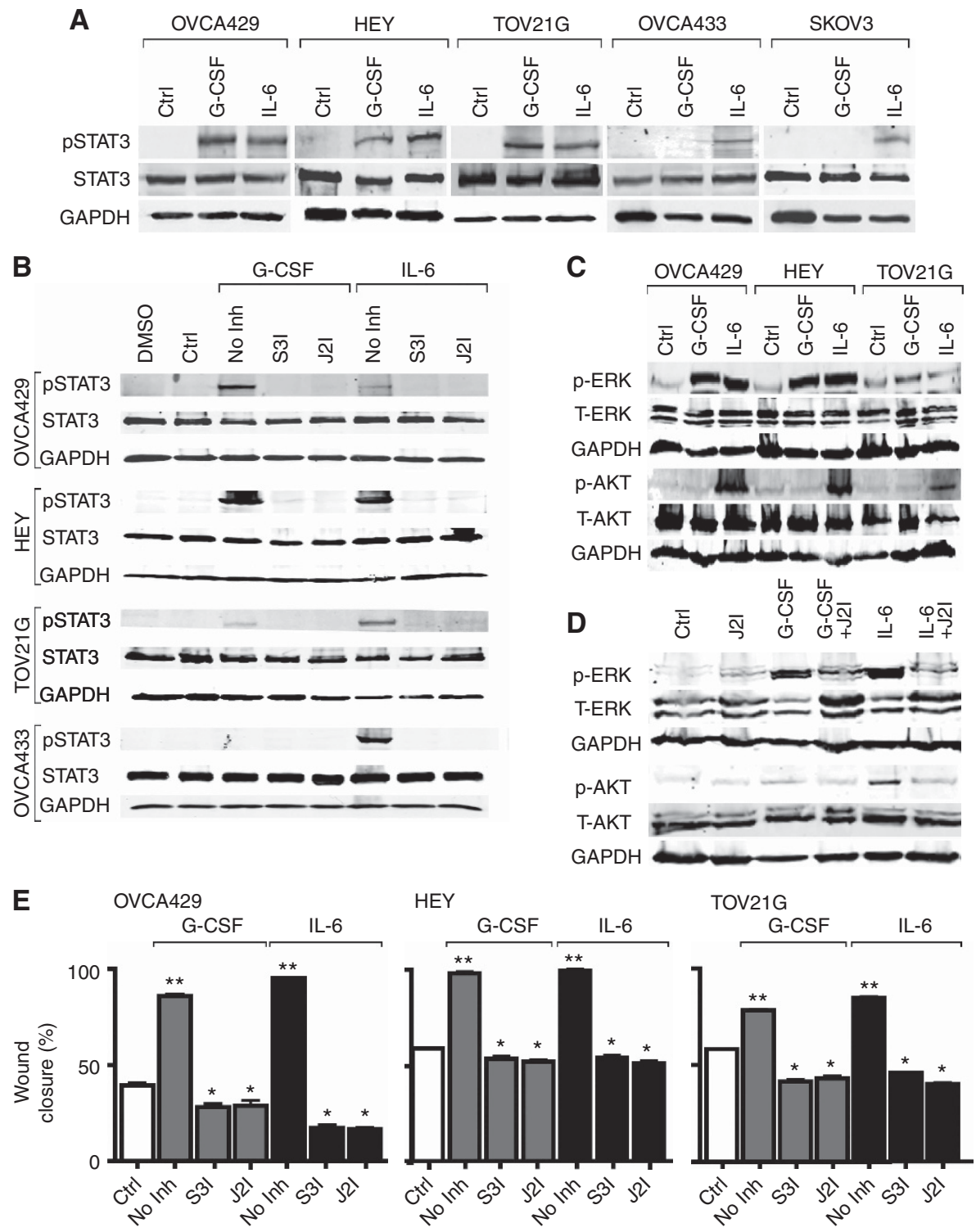

Figure 3. G-CSFR signals via JAK2/STAT3 to mediate its effects on ovarian cancer cells. (A) Activation of STAT3 by G-CSF. Lysates from either untreated (Ctrl) cells or those treated with G-CSF or IL-6 were immunoprecipitated with anti-STAT3 and analysed by western blot with anti-phospho-STAT3 and anti-STAT3 antibodies. The input lysate was analysed using anti-GAPDH to confirm equivalent amounts of protein was examined in each case. Experiments were performed thrice and blots are representative of one experiment. (B) G-CSF-induced STAT3 activation is blocked by specific inhibitors of the JAK2/STAT3 pathway. Cell lysates were prepared from cells either untreated or treated with G-CSF or IL-6 with or without specific inhibitors for STAT3 (S3I) or JAK2 (J2I), as indicated, and analysed for STAT3 phosphorylation as per panel (A). (C-D) G-CSFinduced ERK activation and its inhibition by a JAK2 inhibitor. Cell lysates were prepared from untreated (Ctrl) cells or those treated with G-CSF or IL-6, and analysed by western blot with anti-phospho-ERK, anti-ERK, anti-phospho-AKT, anti-AKT and anti-GAPDH (C). This analysis was repeated for OVCA429 cells in the presence of JAK2 inhibitor (J2I) (D). (E) Migration is blocked by specific inhibitors of the JAK2/STAT3 pathway. Wound closure in OVCA429 cells by G-CSF and IL-6, with or without specific inhibitors for STAT3 or JAK2, as indicated (*P<0.05, ${ }^{\star \star} P<0.005$, compared with control untreated cells).

precursors, endothelial cells and placental tissue (Touw and Van De Geijn, 2007). Signalling through the G-CSFR has several important functions including effective mobilisation of haematopoietic progenitor cells and neutrophilic granulocytes from the bone marrow (Christopher and Link, 2007), as well as stimulation of myelopoiesis (Touw and Van De Geijn, 2007; Liongue et al, 2009a). These properties have seen G-CSF used widely to restore neutrophil numbers following chemotherapy, including for ovarian cancer (Ray-Coquard et al, 2007). Therefore, it is of strong clinical interest whether G-CSF can exert additional effects on ovarian cancer cells. In this study, we examined the expression of G-CSFR in primary ovarian cancer samples and a panel of ovarian cancer cell lines and determined the effects of G-CSF treatment on proliferation, migration and survival.

The G-CSFR has previously been implicated in a diverse range of malignancies. In the case of haematological cancers, its pathogenic effects are mediated via the expression of hyperactive truncated forms, generated through either somatic mutation or disrupted splicing (Liongue et al, 2009b). In solid tumours, mis-expression of both the G-CSFR and its ligand have been implicated. Thus, a significant proportion of invasive bladder carcinoma cells have been shown to express both G-CSF and 

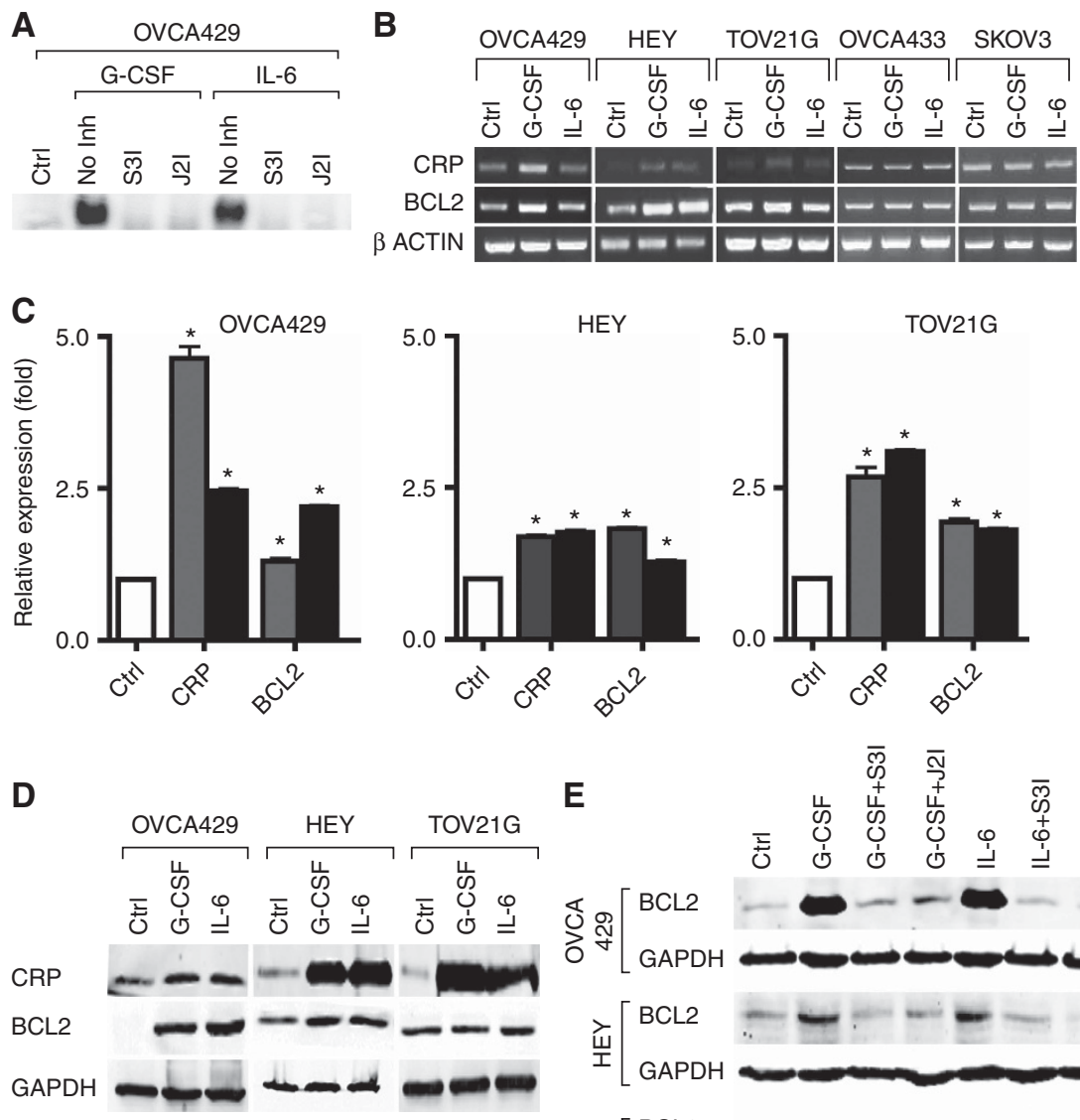

E
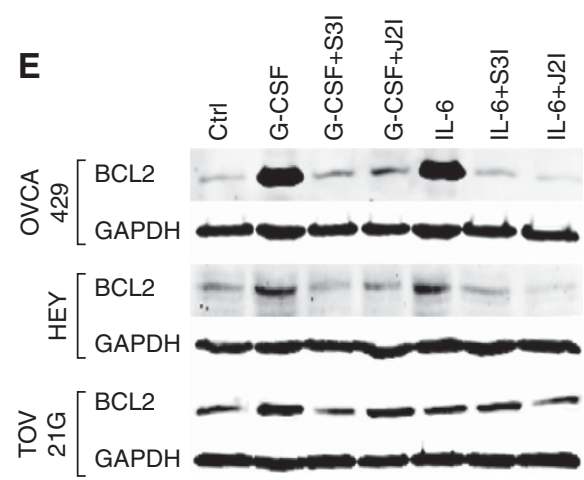

Figure 4. Induction of STAT3 transcriptional activity by G-CSF. (A) Induction of STAT3 DNA binding by G-CSF. Nuclear extracts were prepared from OVCA429 cells either untreated (Ctrl) or stimulated by G-CSF or IL-6 alone (No Inh) or in combination with inhibitors for STAT3 (S3I) or JAK2 (J2I), as indicated. (B-E) Expression of STAT3-responsive genes by G-CSF. Cells either untreated or treated with G-CSF or IL-6 were analysed by semi-quantitative RT-PCR (B), with the fold change determined by subsequent real-time RT-PCR (C, ${ }^{*} P<0.05$ compared with the control). Expression of the encoded proteins in these cells was determined by western blot analysis as indicated (D). For BCL2, this analysis was repeated in the presence of inhibitors for JAK2 (J2I) and STAT3 (S3I) (E).

G-CSFR, with subsequent autocrine signalling contributing to their proliferation and survival in vitro (possibly via STAT3), as well as the size of their induced tumours in vivo (Chakraborty et al, 2004). Both G-CSF and G-CSFR have also been found to be expressed in a series of Ewing's sarcoma patient samples and cell lines, with in vivo tumour growth significantly increased by G-CSF treatment (Morales-Arias et al, 2007). Similarly, dysplastic and squamous cell carcinomas (SCCs) have been shown to exhibit higher expression of G-CSF and G-CSFR than normal controls (Hirai et al, 2001). Granulocyte colony-stimulating factor has also been demonstrated to stimulate the migration of tumour cells derived from patients with head and neck squamous cell carcinoma, with G-CSFR-positive tumours showing increased invasion (Gutschalk et al, 2006).

The role of G-CSF/G-CSFR signalling in ovarian cancer has remained controversial. Previous reports have shown that G-CSFR is expressed on primary ovarian carcinomas (Brandstetter et al, 1998; Ninci et al, 2000; Brandstetter et al, 2001; Savarese et al, 2001). G-CSF is often co-expressed in the cancer cells or surrounding stroma, with the potential for both autocrine and paracrine activation (Savarese et al, 2001). However, the importance of G-CSF expression is ambiguous, with one study suggesting that it does not represent an adverse prognostic factor in ovarian cancer (Munstedt et al, 2010), but another showing that overall survival was worse if present as part of a paracrine loop (Savarese et al, 2001). Granulocyte colony-stimulating factor has also been demonstrated to stimulate the proliferation of a subset of primary ovarian cells and cells lines (Connor et al, 1994; Spinner et al, 1995; Brandstetter et al, 1998), although in other ovarian cancer cells lines increased proliferation was only observed in synergy with EGF (Savarese et al, 2001), and in others there was either no effect (Brandstetter et al, 2001; Savarese et al, 2001), or indeed inhibition (Spinner et al, 1995). Consistent with these studies, our data failed to identify an effect of the G-CSF/G-CSFR pathway on ovarian cancer cell proliferation. In contrast, our work has identified a role for G-CSF/G-CSFR signalling in ovarian cancer cell migration and survival - including in response to chemotherapy agents. This has not been reported previously, but has a parallel in a recent study that autocrine IL-6R can confer chemoresistance, including to cisplatin, in ovarian cancer cells (Wang et al, 2010). Interestingly, G-CSF/G-CSFR signalling directly enhances the motility of human neutrophils (Nakamae-Akahori et al, 2006) and is essential for the directional migration of myeloid cells during embryonic development (Liongue et al, 2009b), and also has a key role in myeloid cell survival (Eyles et al, 2006; Ward, 2007). Our data suggest that these downstream functions are able to be 'hijacked' by ovarian cancer cells.

Granulocyte colony-stimulating factor receptor signalling involves several distinct downstream intracellular signalling cascades, including the JAK2/STAT3 pathway, which ultimately 

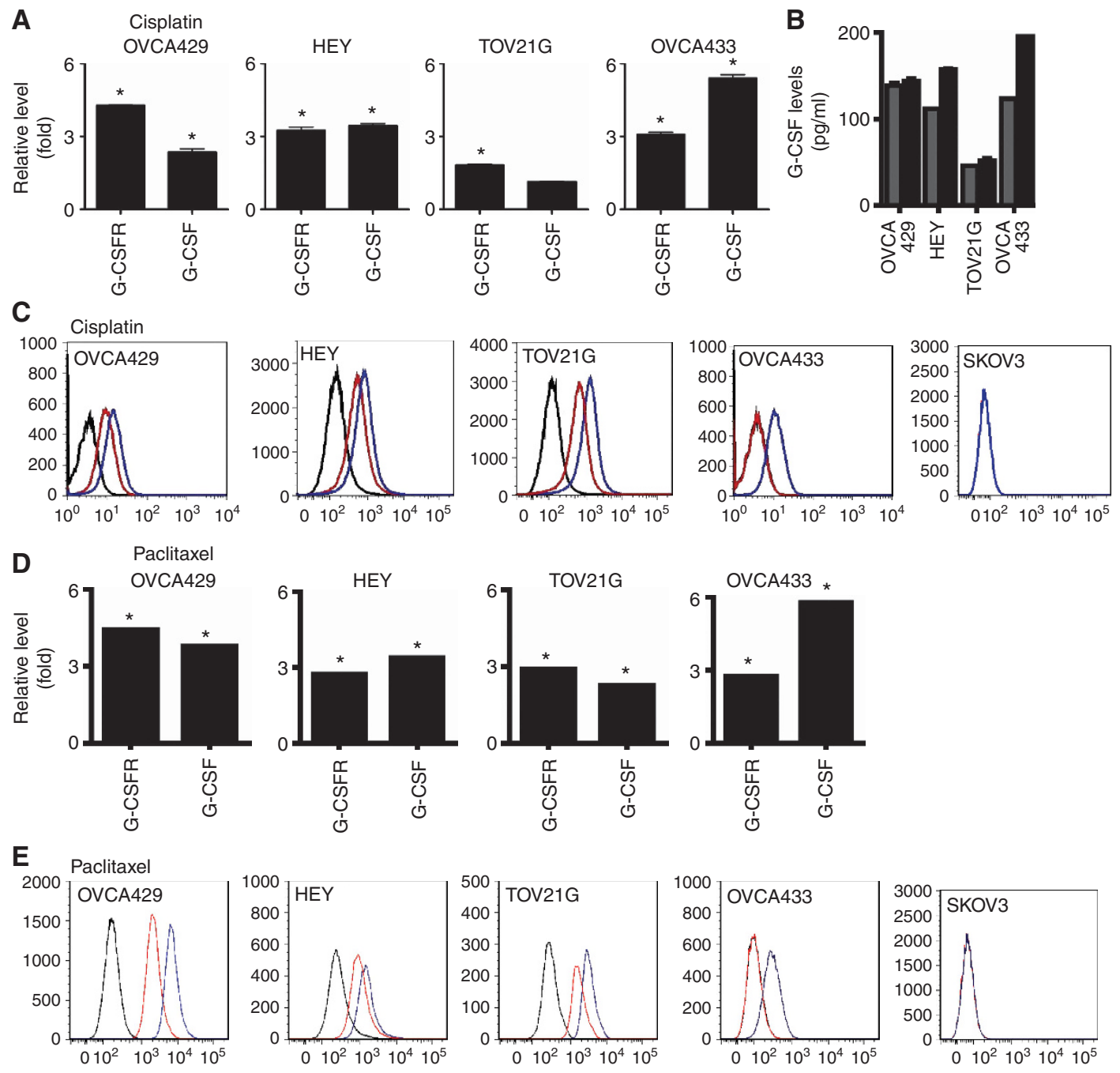

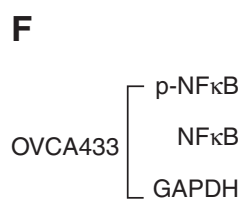

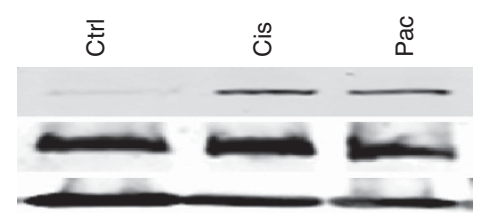

Figure 5. Interaction between chemotherapeutic agents and G-CSF/G-CSFR. (A-E) The effects of the chemotherapeutic agents cisplatin and paclitaxel on the expression of G-CSF/G-CSFR. The impact of 5-day chemotherapy treatment on the indicated ovarian cancer cell lines was determined by RT-PCR for G-CSFR and G-CSF in response to cisplatin (A) or paclitaxel (D), analysis of cell supernatants using ELISA for G-CSF in response to cisplatin (B), or FACS analysis for G-CSFR expression in response to cisplatin (C) or paclitaxel (E) (red line: untreated, blue line: chemotherapy agent) or isotype control (black line). (F) Chemotherapeutic agents activate NF $\kappa$ B. Cell lysates were prepared from OVCA433 cells treated with cisplatin (Cis) or paclitaxel (Pac) as indicated and subjected to western blot analysis with anti-phospho-NF $\kappa$ B, anti-NF $\kappa$ B or anti-GAPDH.

lead to transcriptional changes that impact on survival, proliferation, differentiation and migration (Liongue et al, 2009b). Our data show that the effects of G-CSF/G-CSFR in augmenting both ovarian cancer cell migration and survival are mediated via the JAK2/STAT3 pathway. We have previously shown that G-CSFmediated STAT3 activation contributes to myeloid cell survival (Ward et al, 1999b), while STAT3 activation has additionally been shown to contribute to both migration (Yoon et al, 2013) and chemoresistance (Zhou et al, 2010) of solid tumours. We have also previously demonstrated that chemoresistant ovarian tumours express higher levels of STAT3 in their non-adherent population (Latifi et al, 2012), while cisplatin treatment was able to generate cells with mesenchymal properties (Latifi et al, 2011). In this study, we demonstrate that treatment with either cisplatin or paclitaxel can also enhance expression of both G-CSF and G-CSFR, potentially via $\mathrm{NF} \kappa \mathrm{B}$ activation, which may augment STAT3 activation and possibly contribute to chemoresistance. This is consistent with studies that have demonstrated that $\mathrm{NF} \kappa \mathrm{B}$ can synergise with STAT3 (Yoon et al, 2013) and that NF $\kappa \mathrm{B}$ inhibition can increase the efficacy of paclitaxel (Mabuchi et al, 2004). Finally, three well-established contributors to chemoresistance, the P-glycoprotein pump MDR1 (Goda et al, 2009), the DNA repair component ERCC1 (Kirschner and Melton, 2010) and the detoxifying enzyme GST-pi (Vasieva, 2011) were all induced by G-CSF, providing several mechanisms for mediating the effects observed.

This study has shown that functional G-CSFR is expressed on high-grade ovarian tumours and ovarian cancer cell lines, with G-CSF stimulation able to induce migration and survival signalling in G-CSFR-positive ovarian cancer cell lines via the JAK2/STAT3 pathway. This was enhanced by both cisplatin and paclitaxel in a number of cell lines. G-CSF is commonly used in the context of 

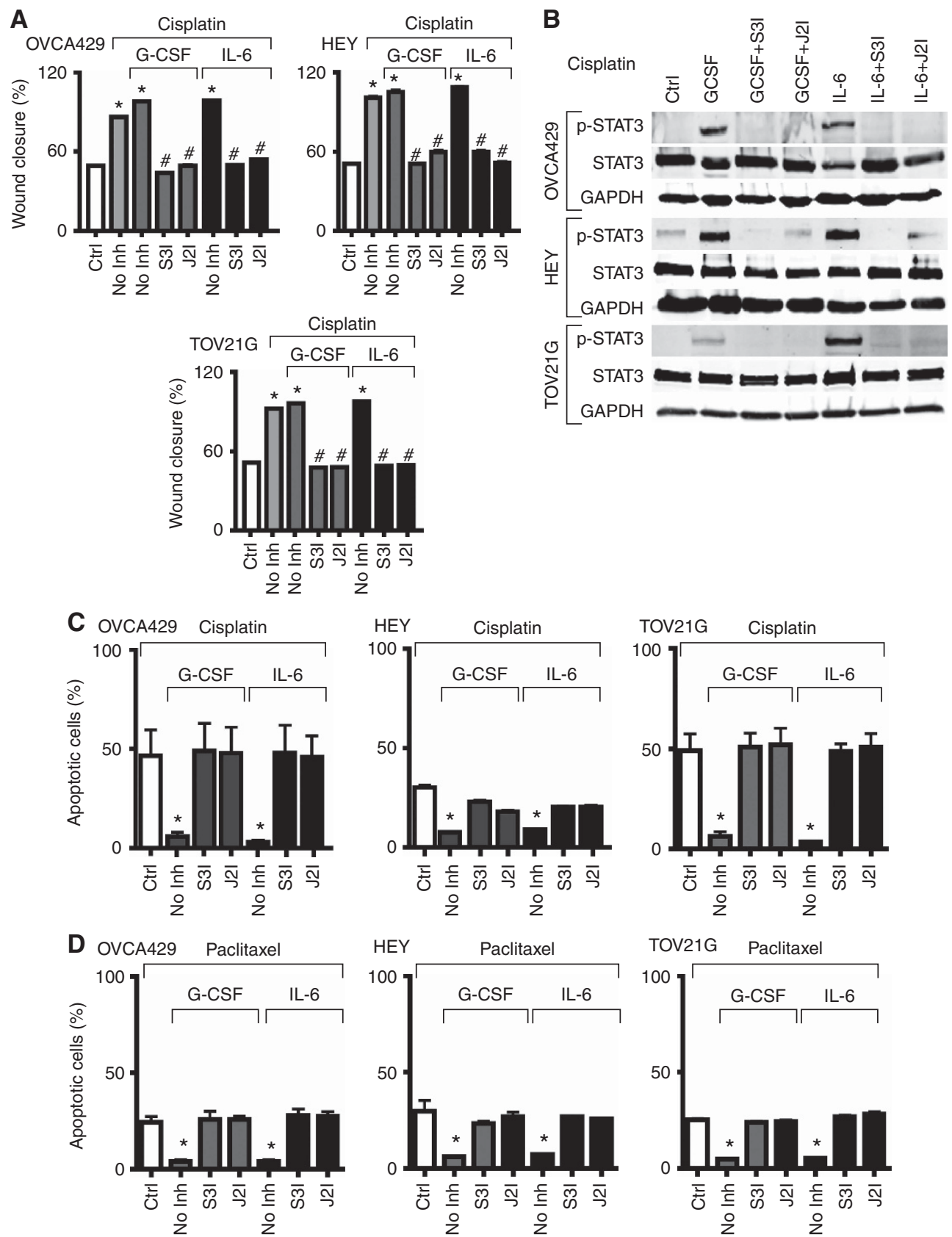

Figure 6. Effects of chemotherapeutic agents on cell survival and migration. (A) Wound-healing assay. Indicated cells were treated with cisplatin alone, or with G-CSF and IL-6 treatment, in the presence or absence of inhibitors for STAT3 (S3I) and JAK2 (J2I). Graph shows the percentage wound closure, expressed as mean + s.e.m. $\left({ }^{\star} P<0.05\right.$ compared with control, ${ }^{\#} P<0.005$ compared with cisplatin). (B) Induction of STAT3 activity. Cell lysates were prepared from OVCA429, HEY and TOV21G cells treated with cisplatin (Cis) as indicated, and subjected to western blot analysis with anti-phospho-STAT3, anti-STAT3 and anti-GAPDH. (C-D) Apoptosis assay. Indicated cells were treated with $12.5 \mathrm{mg} \mathrm{ml}^{-1}$ cisplatin (C) or paclitaxel (D), or with G-CSF and IL-6 treatment, in the presence or absence of inhibitors for STAT3 and JAK2. Graph shows the percentage of apoptotic cells, expressed as mean + s.e.m. ( ${ }^{\star} P<0.005$ compared with chemotherapeutic agent). For TOV21G cells, cisplatin was increased to $20 \mu \mathrm{g} \mathrm{ml}^{-1}$ in order to achieve significant levels of apoptosis.

ovarian cancer to restore neutrophils ablated by standard chemotherapeutic drugs used to treat patients (Yamada et al, 2001). However, if the tumour expresses G-CSFR, either basally or in response to chemotherapy, these treatments could contribute to tumour development by increasing migration and/or survival, irrespective of G-CSF expression. Therefore, screening patient tumours for G-CSFR expression by histology or FACS-based approaches prior to administration of G-CSF could be beneficial, potentially indicating alternative therapies for patients with G-CSFR-positive tumours. Of relevance, co-administration of granulocyte-macrophage CSF factor and recombinant interferon gamma $1 \mathrm{~b}$ in concert with carboplatin treatment in women with recurrent ovarian cancer was shown to be efficacious and elicited a favourable haematological profile (Schmeler et al, 2009), providing a potential option in this regard. Finally, inhibitors of JAK2 and STAT3 have now been developed and used in various clinical settings such as myeloproliferative disorders (Pardanani et al, 2011). Consistent with our data, inhibition of JAK2/STAT3 has been shown to induce apoptosis in ovarian tumours (Kandala and Srivastava, 2012) and increase the chemo-sensitivity of ovarian 

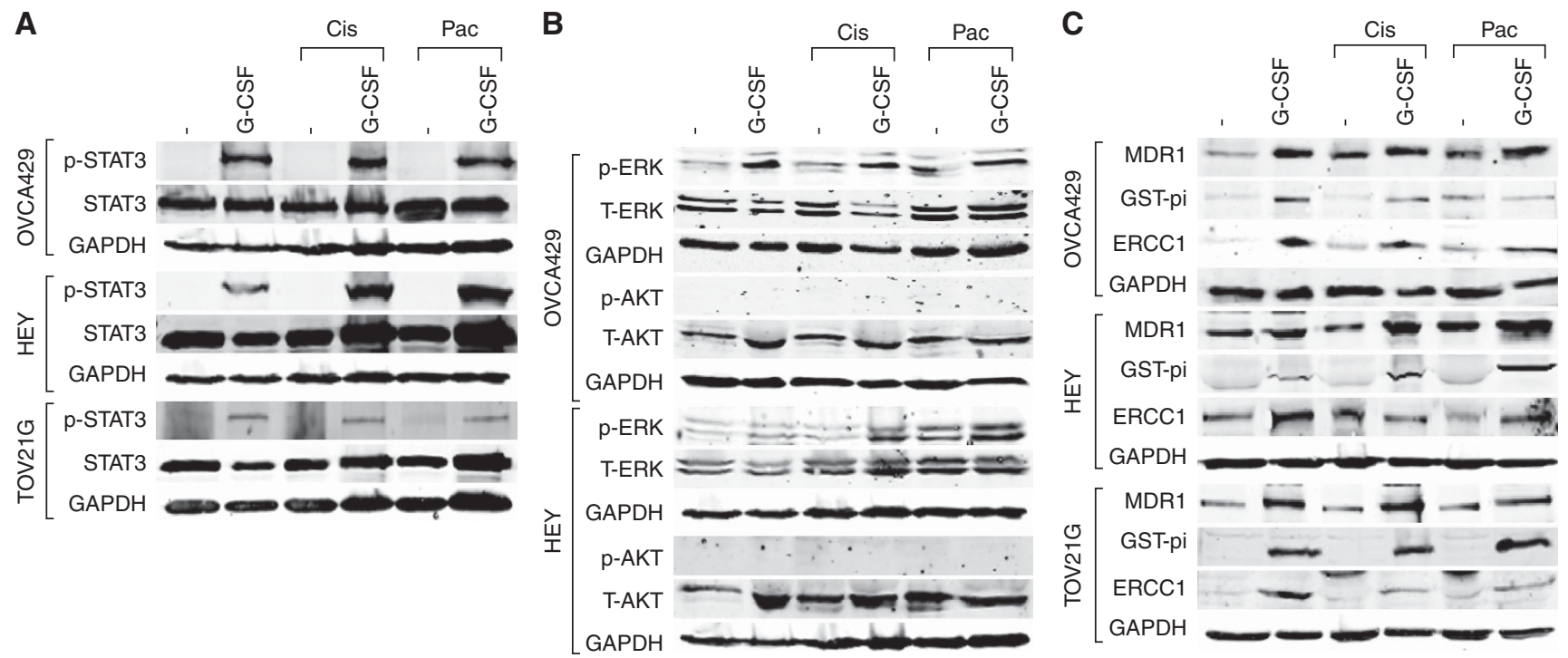

Figure 7. Effects of chemotherapeutic agents on downstream pathways. Cell lysates were prepared from OVCA429, HEY and TOV21G cells treated with cisplatin (Cis) or paclitaxel (Pac) as indicated, and subjected to western blot analysis with anti-phospho-STAT3, anti-STAT3 and anti-GAPDH (A), anti-phospho-ERK, anti-ERK, anti-phospho-AKT, anti-AKT and anti-GAPDH (B), or anti-MDR1, anti-GST-pi, anti-ERCC1 and anti-GAPDH (C).

cancers (Hedvat et al, 2009; Lee et al, 2011). This suggests that inhibitors of the JAK2/STAT3 pathway may also be efficacious in the treatment of chemoresistant ovarian cancer.

\section{ACKNOWLEDGEMENTS}

We recognise the support of a Deakin University International Postgraduate Scheme Award (to JK) and funding from both the Geelong Community Foundation and Atkins Charitable Trust (to ACW).

\section{CONFLICT OF INTEREST}

The authors declare no conflict of interest.

\section{REFERENCES}

Ahmed N, Riley C, Oliva K, Rice G, Quinn M (2005) Ascites induces modulation of alpha6betal integrin and urokinase plasminogen activator receptor expression and associated functions in ovarian carcinoma. Br J Cancer 92: 1475-1485.

Ahmed N, Riley C, Oliva K, Stutt E, Rice GE, Quinn MA (2003) Integrinlinked kinase expression increases with ovarian tumour grade and is sustained by peritoneal tumour fluid. J Pathol 201: 229-237.

Bohlius J, Reiser M, Schwarzer G, Engert A (2003) Impact of granulocyte colony-stimulating factor (CSF) and granulocyte-macrophage CSF in patients with malignant lymphoma: a systematic review. Br J Haematol 122: 413-423.

Bookman MA (2012) First-line chemotherapy in epithelial ovarian cancer. Clin Obstet Gynecol 55: 96-113.

Brandstetter T, Ninci E, Bettendorf H, Perewusnyk G, Stolte J, Herchenbach D, Sellin D, Wagner E, Kochli OR, Bauknecht T (2001) Granulocyte colony-stimulating factor (G-CSF) receptor gene expression of ovarian carcinoma does not correlate with G-CSF caused cell proliferation. Cancer 91: 1372-1383.

Brandstetter T, Ninci E, Falken U, Wagner E, Hess R, Bauknecht T (1998) rhG-CSF affects genes involved in mitogen signalling and early gene expression in the ovarian cancer cell line HEY. Int J Cancer 75: 847-854.
Burleson KM, Boente MP, Pambuccian SE, Skubitz AP (2006) Disaggregation and invasion of ovarian carcinoma ascites spheroids. J Transl Med 4: 6.

Chakraborty A, White SM, Lerner SP (2004) Granulocyte colony-stimulating factor receptor signals for $\beta 1$-integrin expression and adhesion in bladder cancer. Urology 63: 177-183.

Christopher MJ, Link DC (2007) Regulation of neutrophil homeostasis. Curr Opin Hematol 14: 3-8.

Colombo N, Peiretti M, Parma G, Lapresa M, Mancari R, Carinelli S, Sessa C, Castiglione M (2010) Newly diagnosed and relapsed epithelial ovarian carcinoma: ESMO Clinical Practice Guidelines for diagnosis, treatment and follow-up. Ann Oncol 21(Suppl 5): v23-v30.

Colomiere M, Ward AC, Riley C, Trenerry MK, Cameron-Smith D, Findlay J, Ackland L, Ahmed N (2009) Cross talk of signals between EGFR and IL-6R through JAK2/STAT3 mediate epithelial-mesenchymal transition in ovarian carcinomas. Br J Cancer 100: 134-144.

Connor JP, Squatrito RC, Terrell KL, Antisdel BJ, Buller RE (1994) In vitro growth effects of colony-stimulating factors in ovarain cancer. Gynecol Oncol 52: 347-352.

Dunn SM, Coles LS, Lang RK, Gerondakis S, Vadas MA, Shannon MF (1994) Requirement for nuclear factor (NF)-kappa B p65 and NF-interleukin-6 binding elements in the tumor necrosis factor response region of the granulocyte colony-stimulating factor promoter. Blood 83: 2469-2479.

Eyles JL, Roberts AW, Metcalf D, Wicks IP (2006) Granulocyte colonystimulating factor and neutrophils-forgotten mediators of inflammatory disease. Nat Clin Pract Rheumatol 2: 500-510.

Fogh J, Fogh JM, Orfeo T (1977) One hundred and twenty-seven cultured human tumor cell lines producing tumors in nude mice. J Natl Cancer Inst 59: 221-226.

Gao SP, Mark KG, Leslie K, Pao W, Motoi N, Gerald WL, Travis WD, Bornmann W, Veach D, Clarkson B, Bromberg JF (2007) Mutations in the EGFR kinase domain mediates STAT3 activation via IL-6 production in human lung adenocarcinomas. J Clin Invest 117: 3846-3856.

Gits J, Van Leeuwen D, Carroll HP, Touw IP, Ward AC (2006) Multiple pathways contribute to the hyperproliferative responses from truncated granulocyte colony-stimulating factor receptors. Leukemia $\mathbf{2 0 :}$ 2111-2118.

Goda K, Bacso Z, Szabo G (2009) Multidrug resistance through the spectacle of P-glycoprotein. Curr Cancer Drug Targets 9: 281-297.

Godoy-Tundidor S, Cavarretta IT, Fuchs D, Fiechtl M, Steiner H, Friedbichler K, Bartch G, Hobisch A, Culig Z (2005) Interleukin-6 and oncostatin M stimulation of proliferation of prostate cancer 22Rv1 cells through signaling pathways of $\mathrm{p} 38$ mitogen-activated protein kinase and phosphatidylinositol 3-kinase. Prostate 64: 209-216. 
Gonzalez-Martin A, Toledo G, Chiva L (2010) Epithelial ovarian carcinoma: current evidences and future perspectives in the first-line setting. Clin Transl Oncol 12: 418-430.

Grivennikov S, Karin M (2008) Autocrine IL-6 signaling: a key event in tumorigenesis? Cancer Cell 13: 7-9.

Gutschalk CM, Herold-Mende CC, Fusenig NE, Mueller MM (2006) Granulocyte colony-stimulating factor and granulocyte-macrophage colony-stimulating factor promote malignant growth of cells from head and neck squamous cell carcinomas in vivo. Cancer Res 66: 8026-8036.

Hedvat M, Huszar D, Herrmann A, Gozgit JM, Schroeder A, Sheehy A, Buettner R, Proia D, Kowolik CM, Xin H, Armstrong B, Bebernitz G, Weng S, Wang L, Ye M, Mceachern K, Chen H, Morosini D, Bell K, Alimzhanov M, Ioannidis S, Mccoon P, Cao ZA, Yu H, Jove R, Zinda M (2009) The JAK2 inhibitor AZD1480 potently blocks Stat3 signaling and oncogenesis in solid tumors. Cancer Cell 16: 487-497.

Hirai K, Kumakiri M, Fujieda S, Sunaga H, Lao LM, Imamura Y, Ueda K, Fukuda M (2001) Expression of granulocyte colony-stimulating factor and its receptor in epithelial skin tumors. J Dermatol Sci 25: 179-188.

Hudson LG, Zeineldin R, Stack MS (2008) Phenotypic plasticity of neoplastic ovarian epithelium: unique cadherin profiles in tumor progression. Clin Exp Metastasis 25: 643-655.

Jones TR, Kang IH, Wheeler DB, Lindquist RA, Papallo A, Sabatini DM, Golland P, Carpenter AE (2008) CellProfiler Analyst: data exploration and analysis software for complex image-based screens. BMC Bioinformatics 9: 482.

Kamohara H, Ogawa M, Ishiko T, Sakamoto K, Baba H (2007) Leukemia inhibitory factor functions as a growth factor in pancreas carcinoma cells involvement of regulation of LIF and its receptor expression. Int J Oncol 30: $977-983$.

Kandala PK, Srivastava SK (2012) Regulation of Janus-activated kinase-2 (JAK2) by diindolylmethane in ovarian cancer in vitro and in vivo. Drug Discov Ther 6: 94-101.

Karst AM, Drapkin R (2010) Ovarian cancer pathogenesis: a model in evolution. J Oncol 2010: 932371.

Katayama N, Kita K, Kawakami K, Mitani H, Sugawara T, Mizuno S, Yonezawa A, Nishii K, Miwa H, Wada H, Minami N, Shiku H (1998) Granulocyte colony-stimulating factor and its receptor in acute promyelocytic leukemia. Am J Hematol 58: 31-35.

Kirschner K, Melton DW (2010) Multiple roles of the ERCC1-XPF endonuclease in DNA repair and resistance to anticancer drugs. Anticancer Res 30: 3223-3232.

Lagunas VM, Melendez-Zajgla J (2008) Nuclear Factor-kappa B as a resistance factor to platinum-based antineoplasic drugs. Met Based Drugs 2008: 576104.

Lamprecht MR, Sabatini DM, Carpenter AE (2007) CellProfiler: free, versatile software for automated biological image analysis. Biotechniques 42: 71-75.

Latifi A, Abubaker K, Castrechini N, Ward AC, Liongue C, Dobill F, Kumar J, Thompson EW, Quinn MA, Findlay JK, Ahmed N (2011) Cisplatin treatment of primary and metastatic epithelial ovarian carcinomas generates residual cells with mesenchymal stem cell-like profile. J Cell Biochem 112: 2850-2864.

Latifi A, Luwor RB, Bilandzic M, Nazaretian S, Stenvers K, Pyman J, Zhu H, Thompson EW, Quinn MA, Findlay JK, Ahmed N (2012) Isolation and characterization of tumor cells from the ascites of ovarian cancer patients: molecular phenotype of chemoresistant ovarian tumors. PLoS One 7: e46858.

Lawrence T (2009) The nuclear factor NF-kappaB pathway in inflammation. Cold Spring Harb Perspect Biol 1: a001651.

Lee ES, Ko KK, Joe YA, Kang SG, Hong YK (2011) Inhibition of STAT3 reverses drug resistance acquired in temozolomide-resistant human glioma cells. Oncol Lett 2: 115-121.

Lengyel E (2010) Ovarian cancer development and metastasis. Am J Pathol 177: 1053-1064.

Lim R, Ahmed N, Borregaard N, Riley C, Wafai R, Thompson EW, Quinn MA, Rice GE (2007) Neutrophil gelatinase-associated lipocalin (NGAL) an early-screening biomarker for ovarian cancer: NGAL is associated with epidermal growth factor-induced epithelio-mesenchymal transition. Int J Cancer 120: 2426-2434.

Liongue C, Hall C, O'connell B, Crozier P, Ward AC (2009a) Zebrafish granulocyte colony-stimulating factor receptor signalling promotes myelopoiesis and myeloid cell migration. Blood 113: $2535-2546$.
Liongue C, Wright C, Russell AP, Ward AC (2009b) Granulocyte colonystimulating factor receptor: stimulating granulopoiesis and much more. Int J Biochem Cell Biol 41: 2372-2375.

Livak KJ, Schmittgen TD (2001) Analysis of relative gene expression data using real-time quantitative PCR and the $2-\Delta \Delta$ CT method. Methods 25 : 402-408.

Mabuchi S, Ohmichi M, Nishio Y, Hayasaka T, Kimura A, Ohta T, Kawagoe J, Takahashi K, Yada-Hashimoto N, Seino-Noda H, Sakata M, Motoyama T, Kurachi H, Testa JR, Tasaka K, Murata Y (2004) Inhibition of inhibitor of nuclear factor-kappaB phosphorylation increases the efficacy of paclitaxel in in vitro and in vivo ovarian cancer models. Clin Cancer Res 10: $7645-7654$

Morales-Arias J, Meyers PA, Bolontrade MF, Rodriguez N, Zhou Z, Reddy K, Chou AJ, Koshkina NV, Kleinerman ES (2007) Expression of granulocytecolony-stimulating factor and its receptor in human Ewing sarcoma cells and patient tumor specimens: potential consequences of granulocytecolony-stimulating factor administration. Cancer 110: 1568-1577.

Munstedt K, Hackethal A, Eskef K, Hrgovic I, Franke FE (2010) Prognostic relevance of granulocyte colony-stimulating factor in ovarian carcinomas. Arch Gynecol Obstet 282: 301-305.

Nakamae-Akahori M, Kato T, Masuda S, Sakamoto E, Kutsuna H, Hato F, Nishizawa Y, Hino M, Kitagawa S (2006) Enhanced neutrophil motility by granulocyte colony-stimulating factor: the role of extracellular signal-regulated kinase and phosphatidylinositol 3-kinase. Immunology 119: 393-403.

Neijt JP, Engelholm SA, Tuxen MK, Sorensen PG, Hansen M, Sessa C, De Swart CA, Hirsch FR, Lund B, Van Houwelingen HC (2000) Exploratory phase III study of paclitaxel and cisplatin versus paclitaxel and carboplatin in advanced ovarian cancer. J Clin Oncol 18: 3084-3092.

Ninci EB, Brandstetter T, Meinhold-Heerlein I, Bettendorf H, Sellin D, Bauknecht T (2000) G-CSF receptor expression in ovarian cancer. Int J Gynecol Cancer 10: 19-26.

Ouellet V, Zietarska M, Portelance L, Lafontaine J, Madore J, Puiffe ML, Arcand SL, Shen Z, Hebert J, Tonin PN, Provencher DM, Mes-Masson AM (2008) Characterization of three new serous epithelial ovarian cancer cell lines. BMC Cancer 8: 152.

Pardanani A, Gotlib JR, Jamieson C, Cortes JE, Talpaz M, Stone RM, Silverman MH, Gilliland DG, Shorr J, Tefferi A (2011) Safety and efficacy of TG101348, a selective JAK2 inhibitor, in myelofibrosis. J Clin Oncol 29: 789-796.

Provencher DM, Lounis H, Champoux L, Tetrault M, Manderson EN, Wang JC, Eydoux P, Savoie R, Tonin PN, Mes-Masson AM (2000) Characterization of four novel epithelial ovarian cancer cell lines. In Vitro Cell Dev Biol Anim 36: 357-361.

Punnonen R, Teisala K, Kuoppala T, Bennett B, Punnonen J (1998) Cytokine production profiles in the peritoneal fluids of patients with malignant or benign gynecologic tumors. Cancer 83: 788-796.

Ray-Coquard I, Paradiso D, Guastalla JP, Leduc B, Guichard F, Martin C, Chauvenet L, Haddad-Guichard Z, Lepille D, Orfeuvre H, Gautier H, Castera D, Pujade-Lauraine E (2007) Intensified dose of cyclophosphomidee with G-CSF support versus standard dose combined with platinum in first-line treatment of advanced ovarian cancer: a randomised study from the GINECO group. Br J Cancer 97: 1200-1205.

Rose-John S, Waetzig GH, Scheller J, Grotzinger J, Seegert D (2007) The IL-6/sIL-6R complex as a novel target for therapeutic approaches. Expert Opin Ther Targets 11: 613-624.

Sansone P, Storci G, Tavolari S, Guarnieri T, Giovannini C, Taffurelli M, Ceccarelli C, Santini D, Paterini P, Marcu KB, Chieco P, Bonafe M (2007) IL-6 triggers malignant features in mammospheres from human ductal breast carcinoma and normal mammary gland. J Clin Invest 117: 3988-4002.

Savarese TM, Mitchell K, Mcquain C, Campbell CL, Guardiani R, Wuu J, Ollari C, Reale F, Nelson BE, Chen A, Quesenberry PJ (2001)

Coexpression of granulocyte colony stimulating factor and its receptor in primary ovarian carcinomas. Cancer Lett 162: 105-115.

Schmeler KM, Vadhan-Raj S, Ramirez PT, Apte SM, Cohen L, Bassett RL, Iyer RB, Wolf JK, Levenback CL, Gershenson DM, Freedman RS (2009) A phase II study of GM-CSF and rIFN-gammalb plus carboplatin for the treatment of recurrent, platinum-sensitive ovarian, fallopian tube and primary peritoneal cancer. Gynecol Oncol 113: 210-215.

Shield K, Ackland ML, Ahmed N, Rice GE (2009) Multicellular spheroids in ovarian cancer metastases: biology and pathology. Gynecol Oncol 113: $143-148$. 
Shield K, Riley C, Quinn MA, Rice GE, Ackland ML, Ahmed N (2007) Alpha2beta1 integrin affects metastatic potential of ovarian carcinoma spheroids by supporting disaggregation and proteolysis. J Carcinog 6: 11.

Spinner DM, Brandstetter T, Kiechle-Schwarz M, Du Bois A, Angel P, Bauknecht T (1995) c-jun expression and growth stimulation in human ovarian carcinoma cell lines following exposure to cytokines. Int $J$ Cancer 63: 423-427.

Touw IP, Van De Geijn GJ (2007) Granulocyte colony-stimulating factor and its receptor in normal myeloid cell development, leukemia and related blood cell disorders. Front Biosci 12: 800-815.

Vasieva O (2011) The many faces of glutathione transferase pi. Curr Mol Med 11: $129-139$.

Wang J, Shi YK, Wu LY, Wang JW, Yang S, Yang JL, Zhang HZ, Liu SM (2008) Prognostic factors for ovarian metastases from primary gastric cancer. Int J Gynecol 18: 825-832.

Wang Y, Niu XL, Qu Y, Wu J, Zhu YQ, Sun WJ, Li LZ (2010) Autocrine production of interleukin-6 confers cisplatin and paclitaxel resistance in ovarian cancer cells. Cancer Lett 295: 110-123.

Ward AC (2007) The role of the granulocyte colony-stimulating factor receptor (G-CSF-R) in disease. Front Biosci 12: 608-618.

Ward AC, Hermans MHA, Smith L, Van Aesch YM, Schelen AM, Antonissen C, Touw IP (1999a) Tyrosine-dependent and independent mechanisms of STAT3 activation by the human granulocyte colony-stimulating factor (G-CSF) receptor are differentially utilized depending on G-CSF concentration. Blood 93: 113-124.

Ward AC, Smith L, De Koning JP, Van Aesch Y, Touw IP (1999b) Multiple signals mediate proliferation, differentiation and survival from the granulocyte colony-stimulating factor receptor in myeloid 32D cells. J Biol Chem 274: 14956-14962.

Watson JM, Sensintaffar JL, Berek JS, Martinez-Maza O (1990) Constitutive production of interleukin 6 by ovarian cancer cell lines and by primary ovarian tumor cultures. Cancer Res 50: 6959-6965.

Wu KL, Miao H, Khan S (2007) JAK kinases promote invasiveness in VHL-mediated renal cell carcinoma by a suppressor of cytokine signalingregulated, HIF-independent mechanism. Am J Physiol Renal Physiol 293: F1836-F1846.
Xu Z, Jiang Y, Steed H, Davidge S, Fu Y (2010) TGFbeta and EGF synergistically induce a more invasive phenotype of epithelial ovarian cancer cells. Biochem Biophys Res Commun 401: 376-381.

Yamada Y, Tomonaga M, Fukuda H, Hanada S, Utsunomiya A, Tara M, Sano M, Ikeda S, Takatsuki K, Kozuru M, Araki K, Kawano F, Niimi M, Tobinai K, Hotta T, Shimoyama M (2001) A new G-CSF-supported combination chemotherapy, LSG15, for adult T-cell leukaemialymphoma: Japan Clinical Oncology Group Study 9303. Br J Haematol 113: $375-382$.

Yoon J, Cho SJ, Ko YS, Park J, Shin DH, Hwang IC, Han SY, Nam SY, Kim MA, Chang MS, Lee HS, Kim WH, Lee BL (2013) A synergistic interaction between transcription factors nuclear factor-kappaB and signal transducers and activators of transcription 3 promotes gastric cancer cell migration and invasion. BMC Gastroenterol 13: 29.

Zebrowski BK, Liu W, Ramirez K, Akagi Y, Mills GB, Ellis LM (1999) Markedly elevated levels of vascular endothelial growth factor in malignant ascites. Ann Surg Oncol 6: 373-378.

Zeimet AG, Widschwendter M, Knabbe C, Fuchs D, Herold M, Muller-Holzner E, Daxenbichler G, Offner FA, Dapunt O, Marth C (1998) Ascitic interleukin-12 is an independent prognostic factor in ovarian cancer. J Clin Oncol 16: 1861-1868.

Zeineldin R, Muller CY, Stack MS, Hudson LG (2010) Targeting the EGF receptor for ovarian cancer therapy. J Oncol 2010: 414676.

Zhao Q, Wang C, Zhu J, Wang L, Dong S, Zhang G, Tian J (2011) RNAimediated knockdown of cyclooxygenase2 inhibits the growth, invasion and migration of SaOS2 human osteosarcoma cells: a case control study. $J$ Exp Clin Cancer Res 30: 26.

Zhou J, Ong CN, Hur GM, Shen HM (2010) Inhibition of the JAK-STAT3 pathway by andrographolide enhances chemosensitivity of cancer cells to doxorubicin. Biochem Pharmacol 79: 1242-1250.

This work is published under the standard license to publish agreement. After 12 months the work will become freely available and the license terms will switch to a Creative Commons AttributionNonCommercial-Share Alike 3.0 Unported License.

Supplementary Information accompanies this paper on British Journal of Cancer website (http://www.nature.com/bjc) 